\title{
EDITORIAL
}

\section{Malaria: health is wealth}

\author{
Abstract | On 25 April, we celebrate World Malaria Day, an occasion to look at the burden of \\ malaria on the populations in endemic areas. The human cost of malaria is well known, and \\ the link between poverty and malaria is well established. Crucially, decreasing, and possibly \\ eliminating, malaria will have a beneficial economic effect on endemic areas. Therefore, \\ increased funding of malaria research can provide wide-ranging economic benefits beyond \\ the obvious alleviation of human suffering.
}

Malaria has devastating consequences: it strikes over 250 million people worldwide and kills around 1 million people each year, many of whom are children under the age of 5 . Yet the economic costs of malaria get less of the spotlight, even though they also have overwhelmingly harmful effects in endemic areas. In countries where malaria is endemic, the disease decreases the gross domestic product by around $1.3 \%$ each year, which, over the course of decades, has a tremendous influence on the economic development of these countries. The financial burden of malaria in Africa has been estimated to be around US\$12 billion per year. These costs lie in lost productivity owing to illness, decreased productivity after returning to work, time spent as a care giver to a patient or cost of care, lost education and the long-term physical effects of the disease ${ }^{1}$. In addition, there are potential costs that are less easily quantifiable, such as increased family size owing to expected child mortality. Furthermore, there could be decreased investment in malaria-endemic areas. Examples from eradication efforts in Europe during the 1950s show that outside investment increases after the malaria burden decreases.

Malaria, however, is both preventable and treatable. It is transmitted to humans by mosquitoes; early eradication efforts have focused on breaking the cycle of transmission by eliminating the mosquitoes, with varying levels of success. Distribution of insecticidetreated bed nets to prevent bites is an important pillar of the current fight against the disease. Antimalarial drugs also play an important part, although widespread drug resistance has forced the use of more expensive drugs.

Last year, the Organisation for Economic Co-operation and Development gave $\$ 28$ billion in aid to nations in sub-Saharan Africa. However, by increasing the funding of malaria research, as well as many other diseases that have similar effects on the economy of African countries, developed nations can augment their direct economic aid. National funding bodies in developed countries, such as the National Institutes of Health in the United States and the Medical Research Council in the United Kingdom, can promote research by providing additional, specific funds to study the malaria parasites and accelerate the use of any new findings for development of new drug targets and vaccines. If we are serious about finding a long-term solution to improving the quality of life in malaria-endemic regions, there is hardly any better investment than research into malaria and other widespread tropical diseases at both the basic and translational level.

There is reason to be optimistic that funding malaria research can lead to useful medicines and vaccines. Our understanding of the growth of the malaria parasite inside the human and mosquito host is growing rapidly, revealing new drug targets, and we are starting to understand the immune response to the disease. Moreover, the most advanced vaccine candidate, RTS,S, has exhibited encouraging results, and more vaccines are likely to follow. Yet we still have a long way to go. With the solid foundation of knowledge we now have, and with a commitment from funding agencies in developed nations, we should be able to make major strides in the near future. By decreasing the malaria burden, we can relieve human suffering both directly, by preventing disease and deaths, and indirectly, by removing a barrier to economic development.

Mahatma Gandhi said: "it is health that is real wealth, and not pieces of gold and silver". In the case of malaria programmes, health may well lead to wealth - providing a relief to areas that are in need of both.

Sachs, J. \& Malaney, P. The economics and social burden of malaria. Nature 415, 680-685 (2002).

FURTHER INFORMATION

World Malaria Day: http://www.rollbackmalaria.org/worldmalariaday/ Organisation for Economic Co-operation and Development funding: http://www.oecd.org/document/35/0,3343,en $2649 \quad 34487 \quad 42458595 \quad 1 \quad 1$ $11,00 . \mathrm{html}$

ALL LINKS ARE ACTIVE IN THE ONLINE PDF 